\title{
When the Medicine Feeds the Problem; Do Nitrogen Fertilisers and Pesticides Enhance the Nutritional Quality of Crops for Their Pests and Pathogens?
}

\author{
Daisy A. Martinez ${ }^{1 \star \dagger}$, Ulrich E. Loening ${ }^{2}$, Margaret C. Graham ${ }^{3}$ and \\ Alfred Gathorne-Hardy ${ }^{4}$ \\ ${ }^{1}$ Independent Researcher, Gartocharn, United Kingdom, ${ }^{2}$ School of Engineering, University of Edinburgh, Edinburgh, \\ United Kingdom, ${ }^{3}$ School of GeoSciences, University of Edinburgh, Edinburgh, United Kingdom, ${ }^{4}$ Global Academy of \\ Agriculture and Food Security, University of Edinburgh, Edinburgh, United Kingdom
}

\section{OPEN ACCESS}

Edited by:

Everlon Cid Rigobelo,

São Paulo State University, Brazil

Reviewed by:

Leon Etienne Parent

Laval University, Canada

Rafael Antonio Pasini,

Centro de Ensino Superior

Riograndense (CESURG), Brazil

Anamika Sharma,

Virginia Tech, United States

*Correspondence: Daisy A. Martinez daisy.annamaria.martinez@ googlemail.com

${ }^{\dagger}$ Lead contact

Specialty section

This article was submitted to Crop Biology and Sustainability,

a section of the journal

Frontiers in Sustainable Food Systems

Received: 27 April 2021 Accepted: 14 June 2021 Published: 12 July 2021

Citation:

Martinez DA, Loening UE, Graham MC and Gathorne-Hardy A (2021) When the Medicine Feeds the Problem; Do Nitrogen Fertilisers and Pesticides Enhance the Nutritional Quality of Crops for Their Pests and Pathogens? Front. Sustain. Food Syst. 5:701310. doi: 10.3389/fsufs. 2021.701310
The challenge of maximising agricultural productivity encourages growers to apply high volumes of nitrogen $(\mathrm{N})$ fertilisers and pesticides in order to promote and protect yields. Despite these inputs, pests and pathogens (P\&Ps) continue to cause economic losses and challenge food security at local, national, and global scales. P\&Ps are a particular problem in industrial agricultural environments, where large-scale monocultures facilitate rapid growth of crop-adapted P\&P populations. P\&P population growth is strongly dependent upon acquisition of $\mathrm{N}$-resources (e.g., amino acids) from crop tissues, and concentrations of these compounds depend on the metabolic state of the crop which, in turn, is influenced by its growth stage, by environmental conditions, and by agrochemical inputs. In this study we demonstrate that routine applications of pesticides and/or $\mathrm{N}$-fertilisers may inadvertently reinforce the problem of P\&P damage in agriculture by enhancing the nutritional quality of crops for these organisms. $\mathrm{N}$-fertilisation has diverse influences on crops' susceptibility to P\&P damage; $\mathrm{N}$-fertilisers enhance the nutritional quality and "attractiveness" of crops for P\&Ps, and they can also alter crops' expression of the defensive traits (both morphological and chemical) that serve to protect them against these organisms. Exposure of crops to pesticides (including commonly used insecticide, fungicide, and herbicide products) can result in significant metabolic disruption and, consequently, in accumulation of nutritionally valuable amino acids within crop tissues. Importantly, these metabolic changes may not cause visible signs of stress or toxicity in the crop, and may represent an "invisible" mechanism underlying persistent P\&P pressure in the field. Given the intensity of their use worldwide, their far-reaching and destructive consequences for wildlife and overall ecosystem health, and the continued prevalence of P\&P-associated crop damage in agriculture, we recommend that the impacts of these cornerstone agricultural inputs on the nutritional relationship between crops and their P\&Ps are closely examined in order to inform appropriate management for a more secure and sustainable food system.

Keywords: crop, pest, pathogen, nitrogen, pesticide, metabolism, susceptibility, trophobiosis 


\section{INTRODUCTION}

The challenge of maximising agricultural productivity has encouraged growers to apply increasingly large volumes of nitrogen $(\mathrm{N})$ fertilisers and pesticides to cropping systems in order to boost and safeguard yields. The Food and Agriculture Organisation of the United Nations (FAO) estimates that approximately 109 million tonnes of fertiliser $\mathrm{N}$ were applied globally in 2018, along with approximately 4 million tonnes of pesticide active ingredients (FAOSTAT, 2020a,b). These inputs are forecast to increase in the coming years, in step with the continued growth of the human population (Oerke, 2006; Bodirsky et al., 2014).

Alongside the importance of these chemicals in current approaches to industrial food production (by 'industrial' we mean high-yielding agricultural systems that rely on high levels of external inputs), and their considerable significance for the global economy, the environmental costs of agronomic reliance on $\mathrm{N}$ and pesticides are increasingly apparent. Intensive application has resulted in their near-ubiquitous pollution of soils, freshwaters, oceans, and the atmosphere. Agricultural $\mathrm{N}$ inputs substantially alter global $\mathrm{N}$-cycling, with deleterious consequences for biodiversity and overall ecosystem stability, air quality, and contributions to climate forcing both regionally and globally (Fowler et al., 2013). Persistent pesticide residues in agricultural soils, and widespread transport and accumulation of those residues far from their original sites of application by wind, water and erosion raise serious concerns regarding toxicity to non-target organisms, and threats to human health (Silva et al., 2019). Furthermore, despite the diverse arsenal of pesticides applied, agricultural pests, and pathogens (P\&Ps) continue to present significant challenges to food production and security at local, national and global scales, and to cause substantial economic losses (Oerke, 2006; Savary et al., 2019). A recent analysis of the impact of $\mathrm{P} \& \mathrm{P}$ damage on yields of five major food crops - wheat, maize, potato, soybean, and rice-estimated that global yearly losses range between 17 and $23 \%$ for all five crops except for rice, for which the estimate was 30\% (Savary et al., 2019).

There is concern that intensive use of $\mathrm{N}$-fertilisers and pesticides in agriculture may inadvertently reinforce the problem of P\&P-associated damage to crops (Figure 1). Of all the nutrients, $\mathrm{N}$ is required in the highest quantity by plants; sufficient $\mathrm{N}$ availability is vital to support all aspects of crop growth and development. However, fertilisation of crops with $\mathrm{N}$ at high application rates has also been shown to enhance their nutritional quality for, and thus their attractiveness to, P\&Ps. A large body of literature demonstrates that increased $\mathrm{P} \& \mathrm{P}$ damage can result where $\mathrm{N}$ is applied in excess (Mattson, 1980; Walters and Bingham, 2007; Chen et al., 2010; Fagard et al., 2014). In addition, and perhaps paradoxically, treatment of cropping systems with pesticides (e.g., insecticides, fungicides, acaricides, herbicides) may also reinforce subsequent $\mathrm{P} \& \mathrm{P}$ pressure; either by (i) suppressing the natural enemies (e.g., predators/parasitoids) of pest species, thereby creating ecological imbalances that allow pest populations to proliferate, (ii) promoting the evolution of pesticide resistance in some $\mathrm{P} \& \mathrm{P}$ species, and/or (iii) by inducing changes in the tissue biochemistry of crops that render them more susceptible. While the first two of these potential impacts are already welldescribed, and often cited as a causal mechanisms underlying occurrences of "pest resurgence" or "secondary pest outbreak" following pesticide use (e.g., Carson, 1962; Hardin et al., 1995; Bottrell and Schoenly, 2012; Bakker et al., 2020), the third impact has received little attention and is currently much less comprehensively understood.

\section{"Trophobiosis" the Nutritional Relationship Between Agrochemicals, Crops, and Their P\&Ps}

The theory of "trophobiosis" (Chaboussou, 2004) provides initial evidence that intensive use of $\mathrm{N}$-fertilisers and/or pesticides would promote P\&P damage in agriculture. Crops' suitability as hosts for P\&P organisms depends to a large extent upon the availability of soluble nutrients (e.g., amino acids, soluble sugars) in their tissues. That availability depends on the metabolic state of the crop which, in turn, is influenced by its age or growth stage, as well as by external conditions such as soil characteristics, water, light, and agrochemical inputs. Via its conversion to amino acid precursors, $\mathrm{N}$ is used by plants to synthesise proteins. $\mathrm{N}$-fertilisation tends to increase tissue concentrations of soluble $\mathrm{N}$ and amino acids, however, since the uptake of $\mathrm{N}$ can occur more rapidly than its incorporation into primary and secondary metabolic processes (Liu et al., 2018). Since these soluble compounds are major growth limiting nutrient sources for P\&Ps, the trophobiosis theory proposed that their elevated concentrations following fertilisation would create a favourable environment for P\&P organisms to feed and proliferate. Chaboussou also presented data indicating that exposure of crops to a range of pesticides (those in common use at the time of publication) resulted in subtle disruption to crops' primary metabolism and, consequently, in accumulation of amino acids (e.g., glutamine, arginine, asparagine) in crop tissues. In much the same way as for $\mathrm{N}$-fertilisation, it was suggested that routine pesticide exposure could render crops more susceptible to subsequent $\mathrm{P} \& \mathrm{P}$ damage by enhancing the concentration of these nutritionally valuable compounds in their tissues.

In this review, we apply the nutritional focus of the trophobiosis theory as a lens through which to examine the impacts of $\mathrm{N}$-fertilisation and a range of contemporary pesticide products on crops' susceptibility to P\&P damage. We draw together key insights from a broad literature pool spanning a range of interrelated topics, in order to (i) provide an overview of current understanding regarding the complex influence of $\mathrm{N}$-fertilisation on crops' P\&P susceptibility; (ii) investigate the impact of pesticide exposure on crops' internal biochemistry and nutritional quality for P\&P organisms; and (iii) identify key gaps in current understanding, and make recommendations for future research directions. 


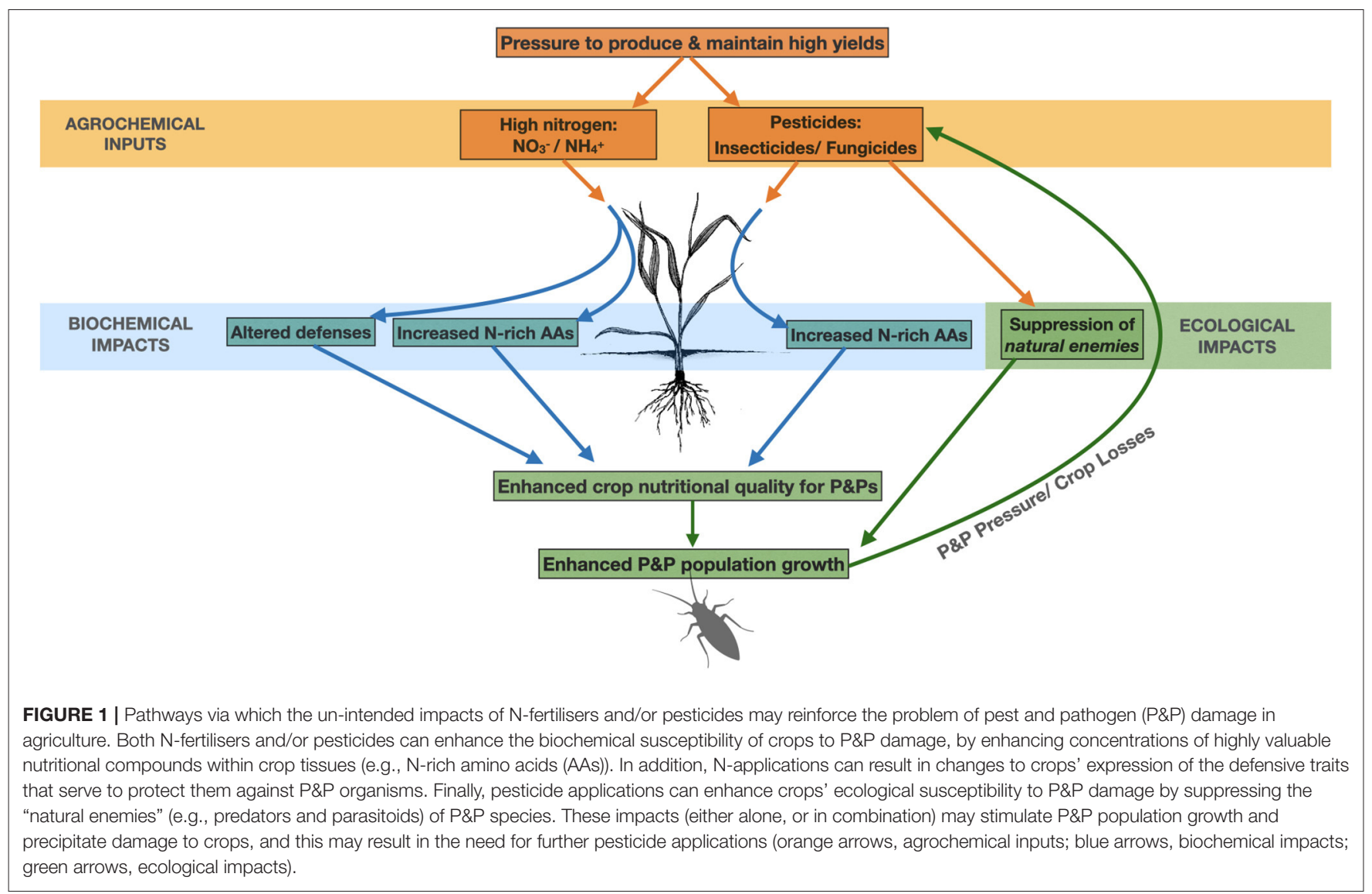

\section{IMPACTS OF N-FERTILISATION ON CROPS' SUSCEPTIBILITY TO P\&PS}

Sufficient $\mathrm{N}$-availability is crucial to support crop development and promote high yields. Plants acquire most of their $\mathrm{N}$ from the soil through plant-mediated uptake of nitrate or ammonium, or additionally through symbiont-mediated atmospheric $\mathrm{N}_{2}$ fixation in legumes. Inside the plant nitrate $\left(\mathrm{NO}_{3}^{-}\right)$is first converted to nitrite $\left(\mathrm{NO}_{2}^{-}\right)$via action of the enzyme nitrate reductase (NR). Nitrite is then converted to ammonium $\left(\mathrm{NH}_{4}^{+}\right)$via the enzyme nitrite reductase $(\mathrm{NiR})$. The ammonium is used for synthesis of amino acids via the glutamate synthase/glutamine-2-oxoglutarate aminotransferase (GOGAT) cycle, and these amino acids become the precursors of complex plant proteins.

It has long been recognised that crops' $\mathrm{N}$-status can influence their interactions with P\&Ps. The underlying mechanisms are complex, however, since $\mathrm{N}$-fertilisation is shown to impact upon both nutritional (see N-fertilisation enhances crop quality for insect herbivores, and $\mathrm{N}$-fertilisation enhances crop quality for pathogenic microbes) and defence (see $\mathrm{N}$-fertilisation influences crops' chemical defences against $P \& P s$ ) components of crop$\mathrm{P} \& \mathrm{P}$ interactions. This phenomenon has been described in previous reviews which focus on the relationship between crop $\mathrm{N}$-nutrition and interactions with phytophagus insect pests (Mattson, 1980; Awmack and Leather, 2002; Chen et al., 2010), and with phytopathogenic microbes (Snoeijers et al., 2000; Walters and Bingham, 2007; Fagard et al., 2014; Sun et al., 2020). Illustrated by examples drawn from these reviews as well as from recently published experimental work, the following sections provide an overview of the influence of $\mathrm{N}$-supply on crops' susceptibility to P\&Ps.

\section{N-Fertilisation Enhances Crop Quality for Insect Herbivores}

Phytophagous insects utilise plant-derived $\mathrm{N}$ compounds as building blocks for biosynthesis of their own tissues (Mattson, 1980). Some insect species assimilate plant-N by chewing plant material and digesting the constituents, whilst others extract soluble $\mathrm{N}$ and amino acids directly by piercing individual cells, and from phloem sap. When presented with choice, most insect herbivores are shown to distinguish between highly fertilised plants containing high concentrations of soluble $\mathrm{N}$ and amino acids, and those of lower nutritional quality (Chen et al., 2010). Insects assess the palatability of plant hosts via a number of morphological properties including the shape, colour, and toughness of leaves, and the presence of pubescence or trichomes (Mattson, 1980; Awmack and Leather, 2002).

$\mathrm{N}$-status has been shown to influence the preference of adult female insects when selecting crop hosts on which to raise new generations of larvae (Prudic et al., 2005; Chen and Ruberson, 2008; Chen et al., 2010; Žanić et al., 2011; Braswell et al., 2019). 
For example, female moths of the beet armyworm (Spodoptera exigua) showed preference for oviposition on cotton plants fertilised with $\mathrm{N}$ at high application rates, compared with controls (Chen and Ruberson, 2008), and the oviposition rate of tobacco whitefly (Bemisia tabaci) was significantly higher on tomatoes (Lycopersicon esculentum Miller cv. Belle) receiving high or intermediate $\mathrm{N}$ rates, compared with those receiving low rates (Žanić et al., 2011).

Once eggs hatch, larvae and nymphs have been shown to develop more rapidly (Glynn et al., 2003; Groenteman et al., 2006; Chen and Ruberson, 2008; Hosseini et al., 2010) and to achieve greater size/body weight when feeding on high$\mathrm{N}$ crops (Nevo and Coll, 2001; Chen and Ruberson, 2008; Hosseini et al., 2010; Aqueel and Leather, 2011; Ren et al., 2013; Larbat et al., 2015; Lange et al., 2019). When three leaf-chewing herbivores; the spotted fireworm (Choristoneura parallela), the sparganothis fruitworm (Sparganothis sulfureana), and the gypsy moth (Lymantria dispar) were raised on cranberry (Vaccinium macrocarpon), larval body weight increased significantly with $\mathrm{N}$ application rate in all three species (Lange et al., 2019). In general, rapid larval development and increased body weight are known to confer greater likelihood of survival to reproductive maturity, and greater overall fecundity (Mattson, 1980; Awmack and Leather, 2002). By contrast, larvae reared on low- $\mathrm{N}$ crops tend to exhibit prolonged development times (Mattson, 1980; Awmack and Leather, 2002; Chen and Ruberson, 2008; Chen et al., 2010; Larbat et al., 2015) and increased mortality (Comadira et al., 2015; Larbat et al., 2015; Lange et al., 2019). A large number of studies document significantly higher rates of insect herbivore population growth, and/or higher ultimate population densities where $\mathrm{N}$ application rates are high, compared with controls (e.g., Hasken and Poehling, 1995; Jauset et al., 2000; Bi et al., 2001; Brodbeck et al., 2001; Nevo and Coll, 2001; Couture et al., 2010; Sauge et al., 2010; Chow et al., 2012; Hu et al., 2016; Larbat et al., 2015; Lange et al., 2019). Finally, a fascinating review by Chen et al. (2010) describes how the "bottom up" effects of Nfertilisation can also influence tritrophic interactions between crops, herbivores, and their natural predators and parasitoids.

The above findings demonstrate that high $\mathrm{N}$-availability can "feed" the problem of pest pressure in agriculture, by enhancing the nutritional quality of crop tissues and supporting rapid population growth of insect herbivores. This highlights an important tradeoff for growers, since any decision to mitigate this effect by reducing fertiliser application rates could limit the overall yield of the crop if $\mathrm{N}$ becomes limiting. A balance must be struck between judicious $\mathrm{N}$-application to minimise nutritional promotion of $\mathrm{P} \& \mathrm{P}$ species, and sufficient $\mathrm{N}$-availability to support crop productivity and quality.

It should also be noted, however, that these trends cannot be assumed to be universal to all crop-pest interactions; since the nature and degree of herbivore response to variations in host $\mathrm{N}$-content is shown to vary both within and between insect feeding guilds (e.g., between leaf chewing or sap-sucking species). A number of factors are likely to contribute to this variation. For example, due to heterogeneous spatial partitioning of $\mathrm{N}$ within the crop, the quantity and quality of $\mathrm{N}$-resources available to a particular pest will depend upon the organs or tissues on which they commonly feed. In addition, insect species vary in their sensitivity to the defensive traits (e.g., structural barriers/toxins/digestibility reducers) synthesised by plants to discourage feeding, and plants' defensive chemistry is also shown to vary significantly with their nutritional status (see $N$-fertilisation influences crops' chemical defences against P\&Ps). In general, phloem-feeding insects (e.g., aphids, plant hoppers, leafhoppers, whiteflies) are shown to be highly responsive to changes in crop N-status, whereas the effects on leaf-chewing species are shown to be less consistent (Mattson, 1980; Altieri and Nicholls, 1995; Awmack and Leather, 2002; Chen et al., 2010). Finally, it is important to note that in some cases, rapid vegetative growth (afforded by high nutrient availability) may allow crops to "keep up" with the biomass removal and/or tissue damage occurring as a result of herbivore feeding (Meyer, 2000).

\section{N-Fertilisation Enhances Crop Quality for Pathogenic Microbes}

Microbial phytopathogens include oomycetes, fungi, bacteria, and viruses. As with insect herbivores, their survival requires acquisition of nitrogenous resources from host plant tissues, and pathogens have evolved diverse strategies for infection and feeding (Solomon et al., 2003; Berger et al., 2007; Divon and Fluhr, 2007). Pathogens with a "biotrophic" lifestyle extract nutrients directly from the apoplast and/or the haustorial matrix of living host cells, whereas "necrotrophic" pathogens kill host cells in advance of invasion and feed on decomposing tissue constituents. The $\mathrm{N}$ resources available to a particular pathogen depend, thus, upon its lifestyle, upon the plant organ or tissue being colonised, and on the overall $\mathrm{N}$-status of the plant. Fertilisation of crops with $\mathrm{N}$ enhances the concentration of soluble $\mathrm{N}$-compounds in crop tissues (including in the apoplast) and thus enriches the pathogen diet (Walters and Bingham, 2007; Fagard et al., 2014; Sun et al., 2020). In addition, Nfertilisation influences plant morphological characteristics such as the branching and expansion of the canopy, which in turn influence the canopy microclimate. The large, dense canopies typical of high-N crops are found to be more conducive to pathogen colonisation and spore transfer than small, sparse ones (Walters and Bingham, 2007; Sun et al., 2020).

Numerous studies have demonstrated that measures of crop disease severity (e.g., the extent of lesion area and/ or pathogenic spore production) were enhanced when $\mathrm{N}$-application rates were increased relative to controls (Walters and Bingham, 2007; Fagard et al., 2014; Huang et al., 2017; Sun et al., 2020). For example, the severity of powdery mildew disease (caused by the biotrophic fungus Erysiphe graminis f.sp. hordei) in seedlings of spring barley (Hordeum vulgare) was strongly influenced by N-supply; both the colony density and cumulative spore production by the pathogen increased significantly with increasing $\mathrm{N}$ application rates to the crop (Jensen and Munk, 1997). The severity of both powdery mildew, and septoria leaf spot disease (the latter caused by the hemi-biotrophic fungus Septoria tritici) was significantly and positively correlated with crop N-status in winter wheat (Triticum aestivum) (Olesen et al., 2003). Also in winter wheat, Neumann et al. (2004) showed that 
rust disease (caused by the biotrophic fungus Puccinia striiformis f.sp. tritici) could be curtailed by reducing $\mathrm{N}$-supply to wheat plants, even though the cultivar used (cv. Brigadier) is known to be particularly susceptible to rust infection.

Collectively, a large body of evidence indicates that high rates of $\mathrm{N}$-fertilisation can increase disease pressure in cropping systems by increasing the nutritional resources available to phytopathogenic microorganisms. Once again, the trade-off is apparent between the beneficial impacts of $\mathrm{N}$ for supporting high yields, and its concurrent promotion of disease pressure which may, in turn, threaten the overall yield and quality of the crop. It would be valuable for future research to explore whether addition of $\mathrm{N}$ in alternative forms (for example via rotations with nitrogen fixing legumes, or application of manure) would enhance crops' nutritional susceptibility to $\mathrm{P} \& \mathrm{P}$ in a similar way.

As with the findings regarding insect herbivory, however, the above trends are not universal and a number of studies report either neutral, or negative effects of $\mathrm{N}$-fertilisation on crop disease severity (e.g., Hoffland et al., 1999, 2000; Lecompte et al., 2010). Findings from a comparative study by Hoffland et al. (2000) emphasise that the relationship between crop $\mathrm{N}$-supply and disease severity is highly pathogen-specific. In parallel laboratory experiments, the authors observed the effect of increasing $\mathrm{N}$ application rates on the susceptibility of tomato plants (L. esculentum) to three different pathogen species. Susceptibility to "bacterial speck" (caused by the hemibiotrophic bacterium Pseudomonas syringae pv. tomato) and also to powdery mildew (caused by the biotrophic fungus Oidium lycopersicum) was significantly and positively correlated with tomato leaf $\mathrm{N}$-concentrations, but crops' $\mathrm{N}$-status had no appreciable effect on their susceptibility to Fusarium wilt disease (caused by the necrotrophic fungus Fusarium oxysporum f.sp. lycopersici). Part of the variation observed in these results (and in the literature more broadly) can be attributed to the differing lifestyles of the pathogens studied (Snoeijers et al., 2000; Solomon et al., 2003; Walters and Bingham, 2007; Fagard et al., 2014). In general, $\mathrm{N}$-fertilisation is expected to strongly enhance the diet (and increase the virulence) of biotrophic pathogens, since these are dependent upon direct extraction of soluble nutrients from living plant cells. The influence of fertilisation on hemibiotrophic and necrotrophic interactions appears to be less consistent (Hoffland et al., 2000; Lecompte et al., 2010; Ballini et al., 2013; Vega et al., 2015; Zhou et al., 2017). On the one hand, the capacity of necrotrophs to kill and decompose host tissues enables them to utilise a broader range of nutrient resources than biotrophs, and this relative "generalism" is thought to buffer the impacts of changes to soluble $\mathrm{N}$ concentrations in plant cells (Solomon et al., 2003). In addition, a plentiful $\mathrm{N}$-supply to the crop supports the endurance of basic cellular metabolism (via maintenance of the GS/GOGAT cycle), and this support may prolong the survival of host cells during interactions with necrotrophs, which specialise in colonisation of weak and/ or senescing tissues (Seifi et al., 2013, 2014). Finally, and in a similar vein to the variation seen between different species of phytophagus insects, phytopathogen species vary in their sensitivity to the defensive compounds produced by plants in order to ward off infection and curtail disease.

\section{N-Fertilisation Influences Crops' Chemical Defences Against P\&Ps}

Various components of plants' innate chemical defences (see Box 1) against P\&Ps can be enhanced, constrained, or remain neutral in response to $\mathrm{N}$-fertilisation (reviewed by Mattson, 1980; Chen et al., 2010; Fagard et al., 2014; Mur et al., 2016; Sun et al., 2020). For example, conditions of high $\mathrm{N}$-availability generally decrease plants' synthesis of C-based defensive compounds, but increase synthesis of predominantly N-based compounds (Sun et al., 2020). A recent review by Sun et al. (2020) emphasises that there can be no unifying model with which to predict the impact of $\mathrm{N}$-fertilisation regimes on crop defence for a given crop-P\&P interaction, since the responses of particular defensive traits are idiosyncratic and vary depending on the biosynthetic pathways involved in, and the resources required for, their expression. In turn, $\mathrm{P} \& \mathrm{P}$ species vary in their sensitivity and responsiveness to these traits (Chen et al., 2010; Sun et al., 2020). Some general patterns in the relationship between $\mathrm{N}$-fertilisation and components of crop defence have been identified, and these will now be outlined in brief. We refer the reader to Sun et al. (2020) for further details.

Because the synthesis of each defensive trait or compound requires investment of precursor molecules and energy, models such as the "Growth Differentiation Balance hypothesis" $(\mathrm{GDBH})$ predict the existence of a physiological trade-off in allocation of plant resources between primary and secondary metabolic pathways (Herms and Mattson, 1992; Massad et al., 2012). According to the GDBH, N-fertilisation stimulates rapid vegetative growth; and, since immature leaves are strong photosynthetic sinks, their growth requires export of photosynthate from mature leaves to support growing meristems. This export drains the pool of carbohydrates available for synthesis of C-based defensive chemicals such as the flavonoids, phenolics, tannins, and terpenoids. By contrast, when N-supply is lessened to the extent that growth is relatively slowed, carbohydrates can accumulate in source leaves and become available for partitioning toward secondary metabolic defences (Herms and Mattson, 1992; Massad et al., 2012). In line with the conclusions of the GDBH, findings from numerous studies indicate that plants' synthesis of various C-based defensive compounds can be significantly attenuated under conditions of high N-availability (Matsuyama and Dimond, 1973; Bryant et al., 1987; Stout et al., 1998; Hoffland et al., 1999; Jauset et al., 2000; Coviella et al., 2002; Glynn et al., 2003; Prudic et al., 2005; Chen and Ruberson, 2008; Sauge et al., 2010; Larbat et al., 2015; Mur et al., 2016).

In contrast to $\mathrm{C}$-based defences, $\mathrm{N}$-fertilisation can enhance plants' expression of some predominantly N-based defensive compounds-for example the chitinases, chitosanases, and $\beta$ glucanases (enzymes which degrade constituents of bacterial and/or fungal cell walls to counter infection)-and other pathogenesis-related (PR) antimicrobial proteins (Stout et al., 1998; Dietrich et al., 2004; Lou and Baldwin, 2004; Sun et al., 2020). Furthermore, recent research indicates that the form of $\mathrm{N}$ available to crops (e.g., $\mathrm{NO}_{3}^{-}, \mathrm{NH}_{4}^{+}$) can also significantly impact the expression of defence, by affecting the biosynthesis 
BOX 1 | Crops' innate defences against P\&P damage.

Plants protect themselves from P\&P damage by expressing a complex constellation of defensive traits. The outermost layer of defence includes a combination of "constitutive" morphological barriers, e.g., the waxy epicuticle/ lignified cell walls, and a host of antimicrobial phytochemicals which inhibit P\&P ingress and development. These phytochemicals include N-based (e.g., alkaloids and non-protein amino acids) as well as carbon (C) based (e.g., phenolics, flavonoids, terpenoids, and tannins) secondary compounds. In addition, plant "recognition" of a pest or pathogen challenge can elicit a suit of induced defence responses; e.g., expression of various defence-related genes, further synthesis of antimicrobial chemicals, and development of the hypersensitive response (HR) and localised plant cell-death (PCD). Defence-related signalling compounds (e.g., reactive oxygen species, nitric oxide, salicylic acid, jasmonic acid) can travel from the initial site of infection or damage throughout distal tissues to confer systemic acquired resistance (SAR) across the whole plant.

of defence-related signalling compounds including nitric oxide, salicylic acid, and the polyamines (Gupta et al., 2013; Mur et al., 2016; Sun et al., 2020).

Although $\mathrm{N}$-availability strongly influences crop defence, it is not yet possible to anticipate the over-all impacts of particular fertiliser regimes without further crop-specific information on the relative effects of $\mathrm{N}$-supply (and form) on the multiple, interrelated components of crops' defensive armoury (see Box 1). Outcomes of individual crop-P\&P interactions in the field will arise from the balance between these interrelated factors, as well as the sensitivity of particular P\&P species to crops' defensive traits. There is likely to be an intermediate range of N-supply rates (particular to each crop, and its growing environment) between which expression of $\mathrm{N}$-responsive defence traits will be optimal. Where high $\mathrm{N}$-availability does undermine crop defence, this impact may compound the stimulatory effects of $\mathrm{N}$-fertilisation on $\mathrm{P} \& \mathrm{P}$ feeding, development and population growth (see $N$-fertilisation enhances crop quality for insect herbivores, and N-fertilisation enhances crop quality for pathogenic microbes).

\section{IMPACTS OF PESTICIDE EXPOSURE ON CROPS' SUSCEPTIBILITY TO P\&PS}

Pesticides have become crucial tools for crop protection in industrial food production. The diversity of modern pesticides, and their specific modes of action allow growers to suppress particular P\&P "target organisms" with no or minimal harm to crops. The following discussion examines the subtle impacts of pesticide exposure on crops' internal biochemistry, and the potential for consequent, un-intended impacts on their nutritional susceptibility to $\mathrm{P} \& \mathrm{P}$ damage.

$\mathrm{P} \& \mathrm{P}$ challenge (e.g., the onset of infection or herbivory) induces rapid re-orientation of crop metabolism and internal biochemistry (Pérez-García et al., 1998; Olea et al., 2004; Pageau et al., 2006; Schwachtje and Baldwin, 2008; Seifi et al., 2013, 2014; Zhou et al., 2015; Thalineau et al., 2018; Wang et al., 2019). Plant metabolic pathways induced in response to $\mathrm{P} \& \mathrm{P}$ challenge are akin to those induced in response to various abiotic stresses (e.g., salt, drought, or light stress) and also during the course of natural tissue senescence (Pageau et al., 2006; Tavernier et al., 2007; Zhou et al., 2015). They are characterised by a transition from Nassimilation to $\mathrm{N}$-remobilisation, and begin with the degradation of ribulose-1,5-biphosphate carboxylase-oxygenase (RuBisCO) and other chloroplastic proteins in the cells of the mesophyll. $\mathrm{NH}_{4}^{+}$released from chloroplast degradation is re-assimilated to glutamine, which becomes a substrate for generation of other N-rich amino acids (Pérez-García et al., 1998; Lea et al., 2007). Newly generated amino acids are either loaded to the phloem for translocation to sites of storage or new growth, or temporarily stored in the cellular vacuole (Masclaux-Daubresse, 2010). The amino acids that commonly accumulate in crop tissues in response to both biotic and/ or abiotic stresses-e.g., glutamine, asparagine, arginine, proline, GABA-are all associated with pathways of $\mathrm{N}$-recycling, remobilisation, and storage (Lea et al., 2007; Seifi et al., 2014).

There is a paradoxical relationship between stress-associated metabolism in plants, and the nutritional requirements of their $\mathrm{P} \& \mathrm{Ps}$, since the N-rich compounds which tend to accumulate in plant tissues during herbivory and/ or during the progress of disease are valuable, growth limiting nutrients for many P\&P organisms (Solomon et al., 2003; Olea et al., 2004; Tavernier et al., 2007; Rico and Preston, 2008; Ward et al., 2010; Fagard et al., 2014; Seifi et al., 2014; Zhou et al., 2015; Huang et al., 2017; Thalineau et al., 2018). Fagard et al. (2014) propose an explanation for this; that co-evolutionary development has led to nutritional adaptation of $\mathrm{P} \& \mathrm{P}$ organisms to utilise the compounds that accumulate in their hosts under conditions of stress.

With regard to Chaboussou's theory of trophobiosis (Chaboussou, 2004), we note that exposure of crops to pesticides (several of those in common use at Chaboussou's time of writing; for example insecticides such as DDT, parathion and thiometon, fungicides such as zineb and maneb, and herbicides such as simazine) was shown to result in protein degradation, and marked accumulation of amino acids in crop tissues (White, 1984; Chaboussou, 2004). Chaboussou proposed that such alterations in the crop biochemical state would render crops more nutritionally valuable, and thus more vulnerable to subsequent herbivory and/or disease.

Data from a number of recently published metabolomic studies (see Box 2) indicates that similar biochemical changes (akin to those associated with stress and/or senescence) can occur in crop tissues following exposure to some contemporary pesticide products (Mahdavi et al., 2015; Serra et al., 2015; Blondel et al., 2016; Li et al., 2019).

Among these, a detailed study by Serra et al. (2015) characterised the response of perennial ryegrass (Lolium perenne) to a suite of chemical "stressors." Rye seedlings were exposed 
BOX 2 | Metabolomic profiling.

Metabolomic profiling uses chromatographic separation coupled with magnetic resonance (NMR) spectroscopy, and/or mass spectrometry (MS) to determine a biochemical phenotype or "fingerprint" of a particular plant tissue at a particular time. When paired with multivariate analyses, these techniques allow researchers to identify particular metabolites (e.g., amino acids, carbohydrates, organic acids, lipids) which vary significantly in concentration between two or more treatment conditions, and thus to visualise and quantify the overall metabolic response of plants to environmental contaminants, or perturbations (Matich et al., 2019).

to "residual" concentrations (low concentrations mimicking residual soil contamination from previous use) of (i) the broadspectrum herbicide glyphosate, (ii) the principle breakdown product of glyphosate aminomethylphosphonic acid (AMPA) and (iii) the triazole fungicide tebuconazole, amongst other pollutants common to agricultural environments. Metabolomic profiling of plant tissue extracts was carried out using gas chromatography mass spectrometry (GC-MS) following exposure treatments. Parallel analyses identified that as well as stressor-specific responses (owing to known chemical modes of action), there were a number of common metabolic response patterns across the exposure treatments. These were characterised by apparent re-orientation of $\mathrm{N}$-metabolism; for example concentrations of the amino acid asparagine were significantly elevated in response to almost all chemical treatment conditions. Asparagine has a particularly high $\mathrm{N}: \mathrm{C}$ ratio, making it a particularly efficient molecule for $\mathrm{N}$ transport and storage (Lea et al., 2007), and its accumulation in treated L. perenne tissues suggests that seedlings may have undergone some degree of stress-induced protein degradation $/ \mathrm{N}$-remobilisation. In addition, the branched-chain amino acids (BCAAs) leucine, valine, and isoleucine were frequently elevated in response to exposure treatments, as was lysine. These may serve as osmotic regulators, and as precursors for a range of secondary metabolites (Mahdavi et al., 2015; Blondel et al., 2016; Huang and Jander, 2017), and have been shown to accumulate in Arabidopsis and other plant species as a result of osmotic stress-induced proteolysis (Huang and Jander, 2017).

A similar response was observed in rice (Oryza sativa L.). A field study conducted by Mahdavi et al. (2015) investigated the metabolic response of rice plants to treatment at recommended rates with the organophosphorus insecticide diazinon. Concentrations of several amino acids from the glutamate family, namely glutamate, glutamine, arginine, and proline were significantly elevated following diazinon treatment. The BCAAs leucine and valine were also elevated, and after an initial depletion (between 24 and $48 \mathrm{~h}$ after treatment) asparagine concentrations increased significantly compared with untreated controls. Along with asparagine, glutamine, and arginine are important $\mathrm{N}$-storage/transport compounds, and are putative markers of stress and/or senescence-induced protein breakdown (Lea et al., 2007). Proline accumulation is common in response to diverse abiotic stress conditions; it is a protectant against oxidative/osmotic stresses, and also functions as an N-storage molecule (Ward et al., 2010; Seifi et al., 2013).
Blondel et al. (2016) exposed maize seedlings (Zea mays) to residual concentrations of two organochlorine pesticides (OCPs); lindane (hexachlorocyclohexane, HCH) and chlordecone (CLD). While use of these insecticides is now strictly prohibited in Europe they are still widely used in parts of Asia and Africa, and their chemical stability renders them highly environmentally persistent (Blondel et al., 2016; Jayaraj et al., 2017). Seedling roots were exposed either to $2.5 \mu \mathrm{M} \mathrm{HCH}$, mimicking baseline soil contamination, or to $25 \mu \mathrm{M} \mathrm{HCH}$ or $2.5 \mu \mathrm{M}$ CLD, both representing residue "hot spots" such as former agricultural sites. 1H-HRMAS NMR-based metabolomic analyses of root tissues were then carried out. Concentrations of GABA and isoleucine were significantly elevated in response to $25 \mu \mathrm{M} \mathrm{HCH}$, and asparagine accumulated remarkably and significantly following both $\mathrm{HCH}$ treatments $(+105$ and $+153 \%$ in response to 2.5 and $25 \mu \mathrm{M} \mathrm{HCH}$, respectively). Metabolic fluctuations in response to CLD were similar to those induced by $\mathrm{HCH}$, although only one increase, that of isoleucine, was statistically significant. The authors concluded that although maize is understood to be relatively tolerant to OPCs, even minute, residual exposures appeared sufficient to trigger some degree of proteolysis and $\mathrm{N}$-remobilisation (Blondel et al., 2016).

Finally, a recent study by Li et al. (2019) exposed 2-weekold seedlings of pak choi (Brassica chinensis) to "residual" concentrations of the widely used neonicotinoid insecticide imidacloprid (IMI). LC-QTOF/MS-based metabolomic analyses were carried out on the 1st and 21st days after exposure (DAE), and these revealed significant fluctuations in a wide array of metabolites. On the 1st DAE tissue concentrations of proline, glutathione, tryptophan, tyrosine, leucine, lysine, threonine, and aspartate were all significantly increased compared with controls, while glutamine and arginine concentrations were reduced. On the 21st DAE glutamine, arginine, aspartate, phenylalanine, tryptophan, and spermidine concentrations were all significantly elevated in treated plant tissues. The overall biomass of IMItreated seedlings was significantly greater than that of controls, and the authors attributed this to hormesis-like stimulation of crop growth, induced by low-level IMI stress.

While none of the studies detailed above were specifically designed to examine the impacts of pesticide-induced biochemical changes on crop-P\&P interactions, their combined findings lead us to a novel hypothesis; that the changes observed (in general characterised by an apparent metabolic shift toward proteolytic breakdown, and free amino acid accumulation) may result in a favourable nutritional environment for P\&P organisms to feed, develop and proliferate (Figure 2). In this way, while pesticides are applied to suppress P\&P organisms in the short 


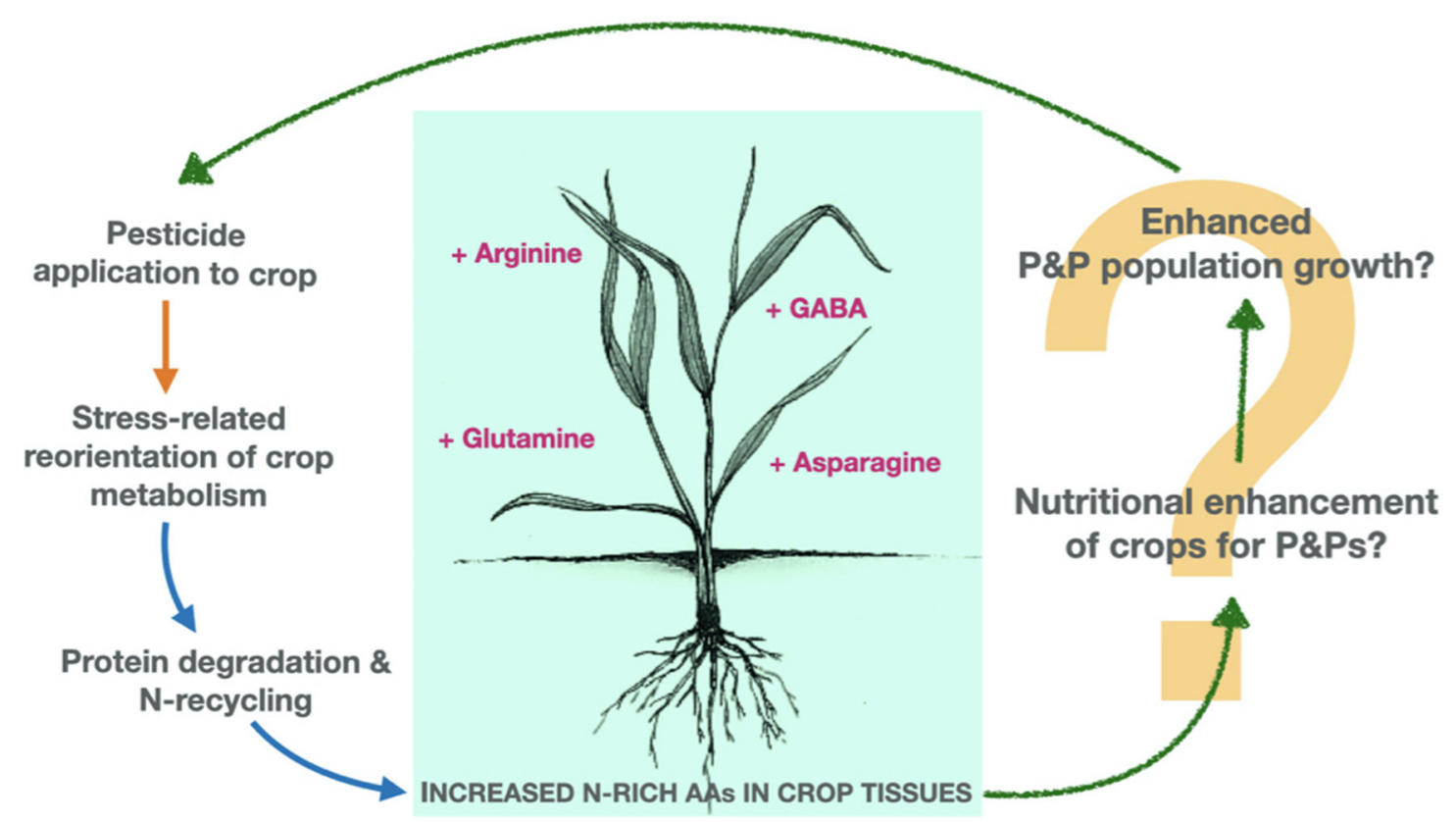

FIGURE 2 | Un-intended impacts of pesticide applications on crops' biochemical susceptibility to subsequent pest and pathogen (P\&P) damage. Exposure of crops to agronomically relevant concentrations of various pesticides can trigger a low-level "stress response" in the crop, resulting in subtle but significant metabolic disruption and accumulation of nutritionally valuable amino acids (AAs) within crop tissues. We hypothesise that pesticide-induced alterations to crop biochemistry may result in a favourable nutritional environment for P\&P organisms (e.g., those not suppressed by the initial pesticide-application) to feed, develop, and proliferate. Subsequent P\&P pressure may then trigger further applications of pesticide (orange arrow, agrochemical inputs; blue arrows, biochemical impacts; green "sketched" arrows, hypothesised ecological impacts).

term, they may simultaneously improve crop nutritional quality for surviving, or in-coming P\&Ps.

\section{OUTSTANDING QUESTIONS AND POTENTIAL INTERACTIONS}

It is important to note that the subtle (but potentially nutritionally important) disruption of primary metabolism observed in the above studies occurred as a common response to several different pesticides (Mahdavi et al., 2015; Serra et al., 2015; Blondel et al., 2016; Li et al., 2019). This effect appears, thus, not to be linked to particular modes of action by active ingredients. Since only a small number of studies are currently available, further research will be highly valuable to determine to what extent this response is expressed in other crop species and cultivars, exposed to other pesticide types and formulations. In addition, since the metabolomic analyses offer us only "snapshots" of the crop biochemical state at particular time-points after exposure, it will be valuable for future studies to determine how long amino acid accumulations persist in effected crop tissues. Many pesticides (and xenobiotics in general) are rapidly degraded within plants, and metabolic disruption is likely to be temporary with crops "recovering" once degradation and detoxification of the applied chemical is substantial. Finally, since changes in the biosynthesis and breakdown of amino acids are certain to impact upon crops' secondary metabolism and the synthesis of defensive compounds (Zeier, 2013), future studies should examine the impacts of pesticide exposure on crops' expression of defence-related traits (see Box 1).

It is possible that pesticide-induced nutritional enhancement of crop tissues may occur in tandem with, and perhaps compound the stimulatory effects of $\mathrm{N}$-fertilisation on $\mathrm{P} \& \mathrm{P}$ population growth (see $N$-fertilisation enhances crop quality for insect herbivores, and $N$-fertilisation enhances crop quality for pathogenic microbes). Finally, it is also important to note that crops' nutritional state (and their quality for P\&Ps) is influenced by a multitude of interrelated factors; which include the relative availability of a diverse array of macro- and micro-nutrients as well as $\mathrm{N}$, the age and stage of development of the crop, and external growing conditions such as local soil characteristics, rainfall, temperature and light. The relative importance of these interacting factors (alongside $\mathrm{N}$ and/or pesticide inputs) in determining crop-P\&P outcomes in the field will likely vary between different crop species and varieties, P\&P species, environments and seasons.

\section{CONCLUSIONS}

The findings presented in this review give support to the original conclusions of the trophobiosis theory. Firstly, we confirm that Nfertilisation can directly enhance the nutritional quality of crop tissues for P\&Ps, and thereby support enhanced P\&P population growth. In addition, recent research reveals that $\mathrm{N}$-fertilisation 
modifies-both quantitatively and qualitatively-crops' expression of their defensive traits.

Secondly, recent metabolomic analyses demonstrate that exposure of crops to pesticides can result in subtle metabolic disruption and, consequently, in accumulation of nutritionally valuable amino acids within crop tissues. This effect may not be sufficient to cause visible signs of toxicity or stress in the plant, and thus it may go unnoticed by growers in the field. We hypothesise that P\&P populations may benefit from this stress-related biochemical state; and resultant $\mathrm{P} \& \mathrm{P}$ pressure may result in a "vicious cycle" of further pesticide applications. Thus, in addition to the more widely recognised ecological impacts associated with pesticides' suppression of predator and parasitoid species, direct, pesticide-induced enhancement of the $\mathrm{P} \& \mathrm{P}$ diet may represent an "invisible" mechanism underlying the persistent problem of $\mathrm{P} \& \mathrm{P}$-damage in agriculture. Our hypothesis remains to be confirmed by multi-factorial trials combining pesticide treatments, biochemical tissue analyses, and experimental P\&P-challenge in a range of crops and environments. In addition, further research should explore the potential for these two mechanisms-nutritional stimulation of $\mathrm{P} \& \mathrm{Ps}$ induced by $\mathrm{N}$-fertilisation, and that induced by

\section{REFERENCES}

Altieri, M. A., and Nicholls, C. I. (1995). Soil fertility management and insect pests: harmonizing soil and plant health in agroecosystems. Soil Till. Res. 72, 203-211. doi: 10.1016/S0167-1987(03)00089-8

Aqueel, M. A., and Leather, S. R. (2011). Effect of nitrogen fertilizer on the growth and survival of Rhopalosiphum padi (L.) and Sitobion avenae (F.) (Homoptera: Aphididae) on different wheat cultivars. Crop Protect. 30, 216-221. doi: 10.1016/j.cropro.2010.09.013

Awmack, C. S., and Leather, S. R. (2002). Host plant quality and fecundity in herbivorous insects. Annu. Rev. Entomol. 47, 817-844. doi: 10.1146/annurev.ento.47.091201.145300

Bakker, L., Van der Werf, W., Tittonell, P., Wyckhuys, K. A. G., and Bianchi, F. J. J. A. (2020). Neonicotinoids in global agriculture: evidence for a new pesticide treadmill? Ecol. Soc. 25:26. doi: 10.5751/ES-11814-250326

Ballini, E., Nguyen, T. T. T., and Morel, J. B. (2013). Diversity and genetics of nitrogen-induced susceptibility to the blast fungus in rice and wheat. Rice 6:32. doi: 10.1186/1939-8433-6-32

Berger, S., Sinha, A. K., and Roitsch, T. (2007). Plant physiology meets phytopathology: plant primary metabolism and plant-pathogen interactions. J. Exp. Bot. 58, 4019-4026. doi: 10.1093/jxb/erm298

Bi, J. L., Ballmer, G. R., Hendrix, D. L., Henneberry, T. J., and Toscano, N. C. (2001). Effect of cotton nitrogen fertilization on Bemisia argentifolii populations and honeydew production. Entomol. Exp. Appl. 99, 25-36. doi: 10.1046/j.1570-7458.2001.00798.x

Blondel, C., Khelalfa, F., Reynaud, S., Fauvelle, F., and Raveton, M. (2016). Effect of organochlorine pesticides exposure on the maize root metabolome assessed using high-resolution magic-angle spinning $1 \mathrm{H}$ NMR spectroscopy. Environ. Pollut. 214, 539-548. doi: 10.1016/j.envpol.2016.04.057

Bodirsky, B. L., Popp, A., Lotze-Campen, L., Dietrich, J. P., Rolinski, S., Weindle, I., et al. (2014). Reactive nitrogen requirements to feed the world in 2050 and potential to mitigate nitrogen pollution. Nat. Commun. 5:3858. doi: $10.1038 /$ ncomms 4858

Bottrell, D. G., and Schoenly, K. G. (2012). Resurrecting the ghost of green revolutions past: the brown planthopper as a recurring threat to highyielding rice production in tropical Asia. J. Asia Pac. Entomol. 15, 122-140. doi: 10.1016/j.aspen.2011.09.004 pesticide exposure-to interact where $\mathrm{N}$ and pesticides are applied together.

Given the intensity of their use worldwide, their far-reaching and destructive consequences for wildlife and overall ecosystem health, and the continued prevalence of $\mathrm{P} \& \mathrm{P}$-associated crop damage in agriculture, we recommend that the impacts of these cornerstone agrochemical inputs on the nutritional relationship between crops and their P\&Ps are closely examined, in order to inform appropriate management for a more secure and sustainable food system.

\section{AUTHOR CONTRIBUTIONS}

UL, AG-H, MG, and DM: conceptualisation and methodology. DM: investigation and writing - original draught. AG-H, UL, and MG: supervision and writing-review and editing. All authors contributed to the article and approved the submitted version.

\section{ACKNOWLEDGMENTS}

We are very grateful to all at the Schiehallion Group for their support of this work.

Braswell, L. R., Reisig, D. D., and Sorenson, C. E. (2019). Helicoverpa zea (Lepidoptera: Noctuidae) oviposition and larval vertical distribution in $\mathrm{Bt}$ cotton under different levels of nitrogen and irrigation. J. Econ. Entomol. 112, 1237-1250. doi: 10.1093/jee/toz023

Brodbeck, B. V., Stavisky, J., Funderburk, J. E., Anderson, P. C., and Olson, S. M. (2001). Flower nitrogen status and populations of Frankliniella occidentalis feeding on Lycopersicon esculentum. Entomol. Exp. Appl. 99, 165-172. doi: 10.1046/j.1570-7458.2001.00814.x

Bryant, J. P., Clausen, T. P., Reichardt, P. B., McCarthy, M. C., and Werner, R. A. (1987). Effect of nitrogen fertilization upon the secondary chemistry and nutritional value of quaking aspen (Populus tremuloides Michx.) leaves for the large aspen tortrix [Choristoneura conflictana (walker)]. Oecologia 73, 513-517. doi: 10.1007/BF003 79408

Carson, R. (1962). Silent Spring. Boston, MA: Houghton Mifflin.

Chaboussou, F. (2004) Healthy Crops: A New Agricultural Revolution. Charlbury: Jon Carpenter Publishing.

Chen, Y., Olson, D. M., and Ruberson, J. R. (2010). Effects of nitrogen fertilization on tritrophic interactions. Arthropod. Plant Interact. 4, 81-94. doi: 10.1007/s11829-010-9092-5

Chen, Y., and Ruberson, J. R. (2008). Impact of variable nitrogen fertilization on arthropods in cotton in Georgia, USA. Agric. Ecosyst. Environ. 126, 281-288. doi: 10.1016/j.agee.2008.02.011

Chow, A., Chau, A., and Heinz, K. M. (2012). Reducing fertilization: a management tactic against western flower thrips on roses. J. Appl. Entomol. 136, 520-529. doi: 10.1111/j.1439-0418.2011.01674.x

Comadira, G., Rasool, B., Karpinska, B., Morris, J., Verrall, S. R., Hedley, P. E., et al. (2015). Nitrogen deficiency in barley (Hordeum vulgare) seedlings induces molecular and metabolic adjustments that trigger aphid resistance. J. Exp. Bot. 66, 3639-3655. doi: 10.1093/jxb/erv276

Couture, J. J., Servi, J. S., and Lindroth, R. L. (2010). Increased nitrogen availability influences predator-prey interactions by altering host-plant quality. Chemoecology 20, 277-284. doi: 10.1007/s00049-010-0058-y

Coviella, C. E., Stipanovic, R. D., and Trumble, J. T. (2002). Plant allocation to defensive compounds: interactions between elevated $\mathrm{CO}_{2}$ and nitrogen in transgenic cotton plants. J. Exp. Bot. 53, 323-331. doi: $10.1093 /$ jexbot/53.367.323 
Dietrich, R., Ploss, K., and Heil, M. (2004). Constitutive and induced resistance to pathogens in Arabidopsis thaliana depends on nitrogen supply. Plant. Cell Environ. 27, 896-906. doi: 10.1111/j.1365-3040.2004.01195.x

Divon, H. H., and Fluhr, R. (2007). Nutrition acquisition strategies during fungal infection of plants. FEMS Microbiol. Lett. 266, 65-74. doi: 10.1111/j.1574-6968.2006.00504.x

Fagard, M., Launay, A., Clément, G., Courtial, J., Dellagi, A., Farjad, M., et al. (2014). Nitrogen metabolism meets phytopathology. J. Exp. Bot. 65, 5643-5656. doi: $10.1093 /$ jxb/eru323

FAOSTAT (2020a). Fertilisers by Nutrient. Available online at: http://www.fao.org/ faostat/en/\#data/RFN

FAOSTAT (2020b). Pesticides Use. Available online at: http://www.fao.org/faostat/ en/\#data/RP

Fowler, D., Coyle, M., Skiba, U., Sutton, M. A., Neil Cape, J., Reis, S., et al. (2013). The global nitrogen cycle in the twenty-first century. Phil. Trans. R. Soc. B 368:20130165. doi: 10.1098/rstb.2013.0164

Glynn, C., Herms, D. A., Egawa, M., Hansen, R., and Mattson, W. J. (2003). Effects of nutrient availability on biomass allocation as well as constitutive and rapid induced herbivore resistance in poplar. Oikos 101, 385-397. doi: 10.1034/j.1600-0706.2003.12089.x

Groenteman, R., Guershon, M., and Coll, M. (2006). Effects of leaf nitrogen content on oviposition site selection, offspring performance, and intraspecific interactions in an omnivorous bug. Ecol. Entomol. 31, 155-161. doi: 10.1111/j.0307-6946.2006.00772.x

Gupta, K. J., Brotman, Y., Segu, S., Zeier, T., Zeier, J., Persjin, S., et al. (2013). The form of nitrogen nutrition affects resistance against Pseudomonas syringae $\mathrm{pv}$. phaseolicola in tobacco. J. Exp. Bot. 64, 553-568. doi: 10.1093/jxb/ers348

Hardin, M. R., Benrey, B., Coll, M., Lamp, W. O., Roderick, G. K., and Barbosa, P. (1995). Arthropod pest resurgence: an overview of potential mechanisms. Crop Protect. 14, 3-18. doi: 10.1016/0261-2194(95)91106-P

Hasken, K. H., and Poehling, H. M. (1995). Effects of different intensities of fertilisers and pesticides on aphids and aphid predators in winter wheat. Agric. Ecosyst. Environ. 52, 45-50. doi: 10.1016/0167-8809(94)09008-U

Herms, D., and Mattson, W. (1992). The dilemma of plants-to grow or defend. Q. Rev. Biol. 67, 283-335. doi: 10.1086/417659

Hoffland, E., Jeger, M. J., and van Beusichem, M. L. (2000). Effect of nitrogen supply rate on disease resistance in tomato depends on the pathogen. Plant Soil 218, 239-247. doi: 10.1023/A:1014960507981

Hoffland, E., van Beusichem, M. L., and Jeger, M. J. (1999). Nitrogen availability and susceptibility of tomato leaves to Botrytis cinerea. Plant Soil 210, 263-272. doi: 10.1023/A:1004661913224

Hosseini, M., Ashouri, A., Enkegaard, A., Goldansaz, S. H., Nassiri Mahalati, M. N., and Hosseininaveh, V. (2010). Performance and population growth rate of the cotton aphid, and associated yield losses in cucumber, under different nitrogen fertilization regimes. Int. J. Pest. Manage. 56, 127-135. doi: 10.1080/096708709032 48827

Hu, X. F., Cheng, C., Luo, F., Chang, Y.-Y., Teng, Q., Men, D.-Y., et al. (2016). Effects of different fertilization practices on the incidence of rice pests and diseases: a three-year case study in Shanghai, in subtropical southeastern China. Field Crops Res. 196, 33-50. doi: 10.1016/j.fcr.2016.06.004

Huang, H., Thu, T. N. T., He, X., Gravot, A., Bernillon, S., Ballini, E., et al. (2017). Increase of fungal pathogenicity and role of plant glutamine in nitrogen-induced susceptibility (NIS) to rice blast. Front Plant Sci. 28:265. doi: $10.3389 /$ fpls.2017.00265

Huang, T., and Jander, G. (2017). Abscisic acid-regulated protein degradation causes osmotic stress-induced accumulation of branched-chain amino acids in Arabidopsis thaliana. Planta 246, 737-747. doi: 10.1007/s00425-017-2727-3

Jauset, A. M., Sarasua, M. J., Avilla, J., and Albajes, R. (2000). Effect of nitrogen fertilization level applied to tomato on the greenhouse whitefly. Crop Prot. 19, 255-261. doi: 10.1016/S0261-2194(00)00016-8

Jayaraj, R., Megha, P., and Sreedev, P. (2017). Organochlorine pesticides, their toxic effects on living organisms and their fate in the environment. Interdiscip. Toxicol. 9, 90-100. doi: 10.1515/intox-2016-0012

Jensen, B., and Munk, L. (1997). Nitrogen-induced changes in colony density and spore production of Erysiphe graminis f. sp. hordei on seedlings of six spring barley cultivars. Plant Pathol. 46, 191-202. doi: 10.1046/j.1365-3059.1997.d01-224.x
Lange, E. S. D., Kyryczenko-Roth, V., Johnson-Cicalese, J., Davenport, J., Vorsa, N., Rodriguez-Saona, C., et al. (2019). Increased nutrient availability decreases insect resistance in cranberry. Agric. For. Entomol. 21, 326-335. doi: 10.1111/afe.12335

Larbat, R., Adamowicz, S., Robin, C., Han, P., Desneaux, N., Le Bot, J., et al. (2015). Interrelated responses of tomato plants and the leaf miner Tuta absoluta to nitrogen supply. Plant Biol. 18, 495-504. doi: 10.1111/plb.12425

Lea, P. J., Sodek, L., Parry, M. A. J., Shewry, P. R., and Halford, N. G. (2007). Asparagine in plants. Ann. Appl. Biol. 150, 1-26. doi: 10.1111/j.1744-7348.2006.00104.x

Lecompte, F., Abro, M. A., and Nicot, P. C. (2010). Contrasted responses of Botrytis cinerea isolates developing on tomato plants grown under different nitrogen nutrition regimes. Plant Pathol. 59, 891-899. doi: 10.1111/j.1365-3059.2010.02320.x

Li, Y., Long, L., Ge, J., Li, H., Zhang, M., Wan, Q., et al. (2019). Effect of imidacloprid uptake from contaminated soils on vegetable growth. J. Agric. Food Chem. 67, 7232-7242. doi: 10.1021/acs.jafc.9b00747

Liu, T., Ren, T., White, P. J., Cong, R., and Lu, J. (2018). Storage nitrogen coordinates leaf expansion and photosynthetic capacity in winter oilseed rape. J. Exp. Bot. 69, 2995-3007. doi: 10.1093/jxb/ery134

Lou, Y., and Baldwin, I. T. (2004). Nitrogen supply influences herbivoreinduced direct and indirect defenses and transcriptional responses in Nicotiana attenuata. Plant Physiol. 135, 496-506. doi: 10.1104/pp.104.040360

Mahdavi, V., Farimani, M. M., Fathi, F., and Ghassempour, A. (2015). A targeted metabolomics approach toward understanding metabolic variations in rice under pesticide stress. Anal. Biochem. 478, 65-72. doi: 10.1016/j.ab.2015.02.021

Masclaux-Daubresse, C. (2010). Nitrogen uptake, assimilation and remobilization in plants: challenges for sustainable and productive agriculture. Ann. Bot. 105, 1141-1157. doi: 10.1093/aob/mcq028

Massad, T. J., Dyer, L. A., and Vega, G. (2012). Costs of defense and a test of the carbon-nutrient balance and growth-differentiation balance hypotheses for two co-occurring classes of plant defense. PLOS ONE 7:e47554. doi: 10.1371/journal.pone.0047554

Matich, E. K., Chavez Soria, N. G., Aga, D. S., and Atilla-Gokcumen, G. E. (2019). Applications of metabolomics in assessing ecological effects of emerging contaminants and pollutants on plants. J. Hazard. Mater. 373, 527-535. doi: 10.1016/j.jhazmat.2019.02.084

Matsuyama, N., and Dimond, A. E. (1973). Effect of nitrogenous fertilizer on biochemical processes that could affect lesion size of rice blast. Phytopathology 63, 1202-1203. doi: 10.1094/Phyto-63-1202

Mattson, W. J. (1980). Herbivory in relation to plant nitrogen content. Annu. Rev. Ecol. Evol. Syst. 11, 119-161. doi: 10.1146/annurev.es.11.110180.001003

Meyer, G. A. (2000). Interactive effects of soil fertility and herbivory on Brassica nigra. Oikos 88, 433-441. doi: 10.1034/j.1600-0706.2000.880221.x

Mur, L. A. J., Simpson, C., Kumari, A., Gupta, A. K., and Gupta, K. J. (2016). Moving nitrogen to the centre of plant defence against pathogens. Ann. Bot. 119, 703-709. doi: 10.1093/aob/mcw179

Neumann, S., Paveley, N. D., Beed, F. D., and Sylvester-Bradley, R. (2004). Nitrogen per unit leaf area affects the upper asymptote of Puccinia striiformis f. sp. tritici epidemics in winter wheat. Plant Pathol. 53, 725-732. doi: 10.1111/j.1365-3059.2004.01107.x

Nevo, E., and Coll, M. (2001). Effect of nitrogen fertilization on Aphis gossypi (Homoptera: Aphididae): variation in size, color, and reproduction. J. Econ. Entomol. 94, 27-32. doi: 10.1603/0022-0493-94.1.27

Oerke, E. C. (2006). Crop losses to pests. J. Agric. Sci. 144, 31-43. doi: $10.1017 /$ S0021859605005708

Olea, F., Pérez-García, A., Cantón, F. R., Rivera, M. E., Cañas, R., Avila, C., et al. (2004). Up-regulation and localization of asparagine synthetase in tomato leaves infected by the bacterial pathogen Pseudomonas syringae. Plant Cell Physiol. 45, 770-780. doi: 10.1093/pcp/pch092

Olesen, J. E., Jørgensen, L. N., Petersen, J., and Mortensen, J. V. (2003). Effects of rate and timing of nitrogen fertilizer on disease control by fungicides in winter wheat. 1. Grain yield and foliar disease control. J. Agric. Sci. 140, 1-13. doi: $10.1017 /$ S0021859602002885

Pageau, K., Reisdorf-Cren, M., Morot-Gaudry, J. F., and Masclaux-Daubresse, C. (2006). The two senescence-related markers, GS1 (cytosolic glutamine synthetase) and GDH (glutamate dehydrogenase), involved in nitrogen mobilization, are differentially regulated during pathogen attack and by stress 
hormones and reactive oxygen species in Nicotiana tabacum L. leaves. J. Exp. Bot. 57, 547-557. doi: 10.1093/jxb/erj035

Pérez-García, A., Pereira, S., Pissarra, J., García Gutiérrez, A., Cazorla, F. M., Salema, R., et al. (1998). Cytosolic localization in tomato mesophyll cells of a novel glutamine synthetase induced in response to bacterial infection or phosphinothricin treatment. Planta 206, 426-434. doi: 10.1007/s004250050418

Prudic, K. L., Oliver, J. C., and Bowers, M. D. (2005). Soil nutrient effects on oviposition preference, larval performance, and chemical defense of a specialist insect herbivore. Oecologia 143, 578-587. doi: 10.1007/s00442-005-0008-5

Ren, L. L., Hardy, G., Liu, Z. D., Wei, W., and Dai, H. G. (2013). Corn defense responses to nitrogen availability and subsequent performance and feeding preferences of beet armyworm (Lepidoptera: Noctuidae). J. Econ. Entomol. 106, 1240-1249. doi: 10.1603/EC12091

Rico, A., and Preston, G. M. (2008). Pseudomonas syringae pv. tomato DC3000 uses constitutive and apoplast-induced nutrient assimilation pathways to catabolize nutrients that are abundant in the tomato apoplast. Mol. Plant Microbe Interact. 21, 269-82. doi: 10.1094/MPMI-21-2-0269

Sauge, M. H., Grechi, I., and Poëssel, J. L. (2010). Nitrogen fertilization effects on Myzus persicae aphid dynamics on peach: vegetative growth allocation or chemical defence? Entomol. Exp. Appl. 136, 123-133. doi: $10.1111 / j .1570-7458.2010 .01008 . x$

Savary, S., Willocquet, L., Pethybridge, S. J., Esker, P., McRoberts, N., and Nelson, A., et al. (2019). The global burden of pathogens and pests on major food crops. Nat. Ecol. Evol. 3, 430-439. doi: 10.1038/s41559-018-0793-y

Schwachtje, J., and Baldwin, I. T. (2008). Why does herbivore attack reconfigure primary metabolism? Plant Physiol. 146, 845-851. doi: 10.1104/pp.107.112490

Seifi, H. S., Curvers, K., De Vieesschauwer, D., Delaere, I., Aziz, A., Höfte, M., et al. (2013). Concurrent overactivation of the cytosolic glutamine synthetase and the GABA shunt in the ABA-deficient sitiens mutant of tomato leads to resistance against Botrytis cinerea. New Phytol. 199, 490-504. doi: 10.1111/nph.12283

Seifi, H. S., Vleesschauwer, D. D., Aziz, A., and Höfte, M. (2014). Modulating plant primary amino acid metabolism as a necrotrophic virulence strategy: The immune-regulatory role of asparagine synthetase in Botrytis cinerea-tomato interaction. Plant Signal. Behav. 9:e27995. doi: 10.4161/psb.27995

Serra, A. A., Couée, I., Renault, D., Gouesbet, G., and Sulmon, C. (2015). Metabolic profiling of Lolium perenne shows functional integration of metabolic responses to diverse subtoxic conditions of chemical stress. J. Exp. Bot. 66, 1801-1816. doi: $10.1093 / \mathrm{jxb} / \mathrm{eru} 518$

Silva, V., Mol, H. G. J., Zomer, P., Tienstra, M., Ritsema, C. J., Geissen, V., et al. (2019). Pesticide residues in European agricultural soilsa hidden reality unfolded. Sci. Total. Environ. 653, 1532-1545. doi: $10.1016 / j . s c i t o t e n v .2018 .10 .441$

Snoeijers, S. S., Pérez-García, A., Joosten, M. H. A. J., and De Wit, P. J. G. M. (2000). The effect of nitrogen on disease development and gene expression in bacterial and fungal plant pathogens. Eur. J. Plant. Pathol. 106, 493-506. doi: 10.1023/A:1008720704105

Solomon, P. S., Tan, K. C., and Oliver, R. P. (2003). The nutrient supply of pathogenic fungi; a fertile field for study. Mol. Plant Pathol. 4, 203-210. doi: 10.1046/j.1364-3703.2003.00161.x

Stout, M. J., Brovont, R. A., and Duffey, S. S. (1998). Effect of nitrogen availability on expression of constitutive and inducible chemical defenses in tomato, Lycopersicon esculentum. J. Chem. Ecol. 24, 945-963. doi: $10.1023 / \mathrm{A}: 1022350100718$
Sun, Y., Wang, M., Mur, L. A. J., Shen, Q., and Guo, S. (2020). Unravelling the roles of nitrogen nutrition in plant disease defences. Int. J. Mol. Sci. 21:572. doi: $10.3390 /$ ijms 21020572

Tavernier, V., Cadiou, S., Pageau, K., Laug,é, R., Reisdorf-Cren, M., Langin, T., et al. (2007). The plant nitrogen mobilization promoted by Colletotrichum lindemuthianum in Phaseolus leaves depends on fungus pathogenicity. J. Exp. Bot. 58, 3351-3360. doi: 10.1093/jxb/erm182

Thalineau, E., Fournier, C., Gravot, A., Wendehenne, D., Jeandroz, S., Truong, H.-N., et al. (2018). Nitrogen modulation of Medicago truncatula resistance to Aphanomyces euteiches depends on plant genotype. Mol. Plant Pathol. 19, 664-676. doi: 10.1111/mpp.12550

Vega, A., Canessa, P., Hoppe, G., Retamal, I., Moyano, T., Canales, J., et al. (2015). Transcriptome analysis reveals regulatory networks underlying differential susceptibility to Botrytis cinerea in response to nitrogen availability in Solanum lycopersicum. Front. Plant Sci. 6, 911. doi: 10.3389/fpls.2015.00911

Walters, D. R., and Bingham, I. J. (2007). Influence of nutrition on disease development caused by fungal pathogens: implications for plant disease control. Ann. Appl. Biol. 151, 307-324. doi: 10.1111/j.1744-7348.2007.00176.x

Wang, M., Gu, Z., Wang, R., Guo, J., Ling, N., Firbank, L. G., et al. (2019). Plant primary metabolism regulated by nitrogen contributes to plant-pathogen interactions. Plant Cell Physiol. 60, 329-342. doi: 10.1093/pcp/pcy211

Ward, J. L., Forcat, S., Beckmann, M., Bennett, M., Miller, S. J., Baker, J. M., et al. (2010). The metabolic transition during disease following infection of Arabidopsis thaliana by Pseudomonas syringae pv. tomato. Plant J. 63, 443-457. doi: 10.1111/j.1365-313X.2010.04254.x

White, T. C. R. (1984). The abundance of invertebrate herbivores in relation to the availability of nitrogen in stressed food plants. Oecologia 63, 90-105. doi: 10.1007/BF00379790

Žanić, K., Dumičić, G., Škaljac, M., Ban, S. G., and Urlić, B. (2011). The effects of nitrogen rate and the ratio of $\mathrm{NO}_{3}^{-}: \mathrm{NH}_{4}^{+}$on Bemisia tabaci populations in hydroponic tomato crops. Crop Protect. 30, 228-233. doi: 10.1016/j.cropro.2010.11.004

Zeier, J. (2013). New insights into the regulation of plant immunity by amino acid metabolic pathways. Plant Cell Environ.36, 2085-2103. doi: 10.1111/pce.12122

Zhou, J., Wang, M., Sun, Y., Gu, Z., Wang, R., Saydin, A., et al. (2017). Nitrate increased cucumber tolerance to Fusarium wilt by regulating fungal toxin production and distribution. Toxins. 9:100. doi: 10.3390/toxins90 30100

Zhou, S., Lou, Y. R., Tzin, V., and Jander, G. (2015). Alteration of plant primary metabolism in response to insect herbivory. Plant Physiol. 169, 1488-1498. doi: $10.1104 /$ pp.15.01405

Conflict of Interest: The authors declare that the research was conducted in the absence of any commercial or financial relationships that could be construed as a potential conflict of interest.

Copyright (c) 2021 Martinez, Loening, Graham and Gathorne-Hardy. This is an open-access article distributed under the terms of the Creative Commons Attribution License (CC BY). The use, distribution or reproduction in other forums is permitted, provided the original author(s) and the copyright owner(s) are credited and that the original publication in this journal is cited, in accordance with accepted academic practice. No use, distribution or reproduction is permitted which does not comply with these terms. 